\title{
Shades, Voice and Mobility: Afar pastoralist and Rift Valley com- munities (re)interpreting literacy and linguistic practices
}

\author{
Kathleen Heugh \\ University of South Australia, Australia and University of \\ the Western Cape, South Africa
}

Kathleen.Heugh@unisa.edu.au

\begin{abstract}
In this paper, narrative data from remote communities in Ethiopia reveal in intimate ways how 'linguistic citizenship' (Stroud 2001) is claimed and exercised to resist educational decisions which are insensitive to the rhythms of pastoral or rural life. Even where communities are distant from the discourses and resources of the centre, individuals and community spokespersons express powerful views which resonate with contemporary global and local concerns of linguistic diversity, literacy and migration. While conventional representations suggest that such communities lack agency and voice, are require externally delivered aid and to be 'spoken for', this article reveals a matrix of articulate positions on language/s, literacy/ies and participation in both primary school and adult education. Amongst the challenges of (re)interpretation for the researcher is a discordant intersection of fluid temporal and spatial positions of researcher and respondent, simultaneously translocal and transnational. Agitated shifts in time and space recast shades and voice for both respondent and researcher. This paper raises questions for research procedures and interpretation of narrative accounts of literacy(ies), linguistics and educational practices on the margins. In particular, the discussion suggests that an understanding of and sensitivity towards the linguistic citizenship of informants as well as the multilayered positions of the researcher, including the researcher's own linguistic citizenship, offer productive theoretical and methodological approaches to ethnographic research.
\end{abstract}

Keywords: Linguistic citizenship, literacy/ies, pastoralists / remote communities, periphery-centre, voice-agency, ethnography

\section{INTRODUCTION}

T he intention in this article is to offer an alternative to a mainstream centred view of communities of people who exist on the peripheries in the global south. ${ }^{1}$ In this case, views of a remote pastoralist (nomadic) community of camel herders in the desert-regions of the Afar depression, and other communities 
further south along the lower reaches of the Great Rift Valley, illustrate that: they have sophisticated understandings of what the centre holds. They have strong views about how they wish to participate with, reinterpret or reject educational decisions of the centre; and most importantly, they express ownership of their own linguistic identities as well as their own constructed identities of the other. Their views towards languages in their own repertoires are indicative of a political agency expressed through their claim on citizenship related to 'language ideologies' (e.g. Jaffe 1999) and rejection of 'language regimes' (Kroskrity 2000, following Laitin 1993) in the linguistic ecology of the country. The concept of 'linguistic citizenship' first introduced by Stroud (2001) captures these dimensions and is used as a point of reference in this article.

The article begins by providing a contextual background to Ethiopia and the intersection of development aid, research practices and the circumstances in which this study arose. the description of the current language education background, situates the purpose of a study of Ethiopian primary schools (Heugh, Benson, Bogale and Gebre Yohannes 2007). The commissioning agents, the Ministry of Education and a consortium of development agencies through the United Nations Development Programme (UNDP), initially made explicit one stated purpose for the study, an evaluation of the language medium policy in primary schools of the country. However, it very soon became evident that there were several competing agendas. The researchers were required to attend to the stated purpose only; the Ministry believed that others would be taken care of in anticipated findings. The language medium policy, since 1994 had been based on home or local language medium for eight years followed by a switch to English medium in secondary school. Recent expensive investment ( $42 \%$ of the teacher education budget) had been re-routed towards a one-off in-service English Language Improvement Programme (ELIP) for teachers. The ministry's implicit belief, perhaps encouraged by the consultant from outside the country, was that this investment would facilitate an earlier change to English medium education in the primary years.

At the same time, Ethiopia is the only country in the world which is currently implementing a multilingual approach to education across the system. Prior to this study there had been no systematic study of this process. The lead researcher recognised that this was an unusual opportunity to gather richly nuanced and unique data. Firstly, the data regarding implementation of a multilingual system would be invaluable for the emerging field. Secondly, if the shift towards English were to become established, this would alter the linguistic ecology of the education system, and this would have an impact on the implementation of the multilingual policy. Data collected at this time would be significant for later comparative purposes.

The paper is written from the intimate perspective of a researcher who attempts to participate in a spatial, temporal and reflexive journey when investigating the language and literacy practices of remote communities. The aim is to unveil and discard as many layers of positions and pre-formulated views of what to expect. One might see this as aiming at as bare a slate as possible. The journey is therefore both physical (spatial and temporal) and metaphorical (inner) and it has methodological and theoretical implications for ethnographic research. Most methodological studies place the spotlight on the subject of enquiry, and the patience 
required to peel away or slice through layers of obfuscating but protective cloaking of position and need. The methodological perspective here, flowing from an understanding of linguistic citizenship as a lens which reveals intensely political agency and voice, is multi-directional. As a researcher, one may need to plumb the depths of one's own linguistic citizenship and how this has evolved as much as that of the respondent. If one translates the metaphor - there are two onions or more if intermediaries are involved.

The discussion in the paper turns from the methodological frame towards the narrative accounts of community spokespersons and what these reveal of co-operation with and resistance towards both regional and federal education authorities. An understanding of linguistic citizenship, or a conscious recognition of the voice and agency of informants, facilitates interpretations which are raw, unpolished and deeply intimate. It is a negotiation of meaning amongst informants, the intermediaries, and the researcher that is interpreted here. The article concludes, drawing attention to linguistic citizenship as an enriching methodological approach which has theoretical implications for ethnographic research. It permits respondents' views to emerge in ways which counter the dominant language regimes of the centre. It also ensures that it is the respondents' views in the horizontal spaces, rather than authoritarian vertical stances, which are the focus of enquiry. It is hoped that the discussion here may contribute to critical reflection of research practice and praxis in which the researcher's own linguistic citizenship cannot be overlooked.

\section{CONTEXTUAL BACKGROUND}

$\mathrm{E}$ thiopia, one of the poorest countries of the world, is a country with: a significant number of pastoralist (nomadic) communities traversing (semi-) desert-like regions; and a significant concentration of people (at once rooted and mobile) along the lower flood plains of the Rift Valley. Each of these environments is geographically remote, distanced from the domestic and international centres of political and economic power, and susceptible to ravages of climate change. Despite federal and international frameworks of commitment to school retention and gender equality, girls, especially in the eastern regions of the country succumb to abduction, early marriage and forced migration, exacerbated by cross-border raids from Somalia as well as Yemen and Saudi Arabia (via Djibouti). It is thus understandable that a researcher might slip into a perspective which views such communities as without voice or agency.

This is a country in which $85 \%$ of its 74 million people (Population Census Commission, PCC, 2008) are engaged in agriculture and so live in rural or remote settings. An estimated 12 to 14 million are pastoralists, a term which includes 'herders, migrant fishers, gold sifters, huntergatherers and other mobile populations across Ethiopia' (PACT Ethiopia 2008:56). Viewed from a western perspective, access to schools by communities on the fringes is often vexed and transient at best, even though formal education has undergone rapid expansion since a change in government in the early 1990 s. There is a long history ( 150 years) of resistance to use of one Ethiopian language, Amharic, as the language of governance and education across the country. Approximately $73 \%$ of the population in regions further from the capital city, Addis Ababa, and the Amhara region have at one time or another engaged in various struggles to resist a vertically imposed language regime (exclusive use of 
Amharic for governance, education and the formal economy) intended for political domination.

The consequence of this resistance has led to very low school enrolment, particularly amongst communities who use one of the 80 Ethiopian languages other than Amharic. Political change in the early 1990s was followed by the Education and Training policy (MoE 1994) based on a principle of ethnolinguistic self-determination within eleven administrative (including two city-state) regions. This policy replaced the earlier vertical use of Amharic, as the language of primary school education and regional governance. English, spoken by $0.3 \%$ of the population (CSA 2007) was used for the fraction of citizens who managed to proceed into secondary education and beyond. Nevertheless, the historical circumstances and earlier resistance to formal education has meant that enrolment in Ethiopia has lagged behind that of other sub-Saharan countries, which, in turn is very low in relation to international statistics.

Low participation, retention and throughput to secondary school during the 1990s and first decade of the 21st century are a source of concern in a historical period in which the UNESCO Education for All goals and time-frames have drawn international agreement on priorities that include universal participation in primary education and gender equality. Attached to the coattails of these frameworks and agreements is a large coterie of development agencies heavily laden with aid packages and educational consultants eagerly offering 'assistance' in the form of ready-made education curricula, programmes, learning materials, assessments, evaluations and other resources, designed for European and North American clienteles, which they are willing to translocate or re-sell to communities of the South. Beguiling resources such as these have a certain cachet in post-colonial African contexts. They seem to hold out the promise of prising open narrow corridors which lead towards a globalised world of rich rewards and hence they appear to offer a flight from poverty, with all its attendant ills.

Such interventions are not new to African countries. Nineteenth century evangelism, missionary activity and education, gave way to colonial and postcolonial education in most parts of Africa during the twentieth century. In each of these historical periods, different generations of expertise from without were introduced as offering access to modernity and Western or Northern epistemologies, scripts and texts. Yet after 200 years, not much has changed for poor people on the margins of society (Obanya 1999; Bamgbose 2000, Ouane 2003) and few on the continent access the promised bounty. This phenomenon, more recently accompanied by the instruments and apparatus of Western political economy in the guise of World Bank or other international development agencies' templates for educational reform, has been at odds with pre-colonial ecologies of: governance, economy and education; and linguistic, literary and faith-based practices. Most countries in Africa have experienced successive layers of exogenous systems which have been cast over complex endogenous practices. Instead of finding liberty or access to what is promised in the north, African communities have found themselves increasingly impoverished and simultaneously often distanced from access to endogenous literary and or educational traditions, especially where these coexist with Islamic rather than Christian faith (O. Alidou 2005; Heugh 2011 a).

Ethiopia, however, has had a different trajectory from most other African countries. First, the longest literary 
tradition in Africa emerged from this country by the second century AD. Modern Amharic text uses Ethiopic script that followed Ge'ez, which was used for early sacred texts of the Ethiopic Coptic church. Coptic Christianity is the dominant faith of Ethiopia, particularly in the western regions of the country, and has been a significant conveyer of scholarship for centuries. A second literary tradition also related to sacred texts, in Arabic, has been part of the faith-based, literary and educational ecology, particularly in the eastern parts of Ethiopia (Somali and Afar regions) from the seventh century onwards. Attendance in Qur'anic schools in these parts (see also: Carr-Hill and Peart 2005; PACT 2008), even by nomadic children has been a feature of social cohesion. Just as the resurgence of Islam over the last fifty years has increased participation in Qur'anic schools across much of North and West Africa, the pattern of attendance of what may be understood as alternative or non-formal education practices continues amongst Muslim communities who are mobile in neighbouring Somalia as well as in the Somali, Afar and Oromiya regions of Ethiopia. The second major difference between Ethiopia and other African countries is that it never succumbed to colonisation, although it did experience a short Italian occupation during the World War II. The Ethiopic and Islamic faith-based literary traditions and absence of colonial interference has meant that internal systems and ecologies did not, for the most part, articulate with Western traditions until the second half of the twentieth century, after Britain offered Ethiopia assistance to eject the Italians during World War II. They were in fact engaged along different trajectories.

Western histories and literature, nevertheless, have and continue to position people of Africa as without literacy and education. If one understands: literacy as that delivered through the Latin script, education as that based on Western epistemology, and schools which look like those in Europe and North America, one might argue thus. Such representation, however, is ahistorical, unreliable and invalid. There is alternative evidence of a long history of scholarship; multi-age teaching and learning groups; portable classrooms under trees or temporary shelters; and literary traditions in Africa. However, this has been obscured, marginalised and rendered invisible during the colonial period, most forcibly during the French colonial administration of many West African countries (H. Alidou 2004; O. Alidou 2005; Heugh 2006, 2011 a). Having been 'invisibilised' does not mean that local practices have ceased nor does this mean that they have remained static and impervious to socio-economic or political changes evident in the mainstream. Nevertheless, a positioning of African communities as 'without literacy' is accompanied by one in which African communities are cast as, on the one hand, 'orate', yet, simultaneously as 'without voice' or agency (see also: Carr-Hill and Peart 2005; O. Alidou 2005; Brocklesby et al. 2009). The inherent contradiction within this view and the ahistorical understanding of horizontal layers of literary, faith, educational and economic practices of the continent lie at the heart of misguided, inappropriate, and fundamentally flawed responses to poverty and famine.

The overlay of the Western perspective, literally and figuratively, looking downwards through a vertically positioned lens upon Africa, has been persuasive and enduring despite evidence which challenges such a view. In part this may be ascribed to an enduring 'Orientalist' perception of Islam within Europe, dating back to the Crusades of the 11th century, and also to a comprehensive 
failure to recognise the significance of scholarship and literary practices which accompanied the spread of Islam from the Horn of Africa across the North and into West Africa from the 7th century onwards (e.g. Foucault 1977, Said 1979, O. Alidou 2005). Turning a blind eye and deaf ear to productive discourses which exist within intricate ecologies of mobility and horizontal systems, especially when this coincides with Islam, has made way for a recasting of African communities as lacking and thus requiring of international literacy, education, modernity and Christianity or secularism. Communities on the geographic margins are further cast as presenting an increased degree of need or difficulty for those whose purpose it is to intervene.

Nomadic populations are generally included under the category of disadvantaged and hard-to-reach groups and represent a particular challenge for development in general and education in particular.... [T]he rate of primary school enrolment of children for nomadic communities is significantly below the national average.... [T] heir low participation rates ... contribute to denying them the chance to effectively participate in planning and development activities (Kabbaj and Matsuura 2005: 5-6).

Post-colonial African governments have purchased these views and thus become tied into long-term debt which is to be repaid via the rather elusive pursuit of globalised homogeneity. Despite Ethiopia's escape of colonisation, these discourses have nevertheless crossed political boundaries and are evident particularly where pastoralists and other hard-toreach communities live at significant distances from the country's administrative centre, Addis Ababa. Western accounts of these communities are that they lack voice or agency. Opportunity has been seized in which Western systems and epistemologies have brought about rapid alterations to the political, educational, and economic ecology of the country over the last two decades, escalating more recently. However, there have been recent challenges to this misrepresentation of communities on the margins which demonstrate that pastoralists, for example, have articulate voice and stance in relation to education, participation and citizenship (Krätli 2001, Carr-Hill and Peart 2005, PACT Ethiopia 2008, Brocklesby et al. 2009). Just as earlier Western-oriented educational systems in West, East and Southern Africa passed over Indigenous Knowledge (IK) systems and practices, newer changes in Ethiopia have not articulated productively with easily accessible networks of Qur'anic schools in the eastern side of the country. In neighbouring Somalia, which has terrain and conditions similar to the Somali and Afar regions of Ethiopia, it is estimated that $85 \%$ of pastoralists are within $0.5 \mathrm{~km}$ of such a school, whereas only $28 \%$ live within this distance of formal primary schools, and $0 \%$ in reach of secondary schools (Maxey 2004 in PACT 2008: 27). The proximity to Qur'anic schools is often facilitated by their portability and thus their architecture matches that of the communities whose needs they serve. Addis Ababa, the country's capital is located in the Coptic Christian dominant part of the country and the proximal distance between this centre of power and the West is closer on a philosophical level, and less threatening to the Orientalist position, than the Islamic dominant eastern side of the country. Thus it becomes easier for the agents of the large international development organisations to view educational provision through the lens of the international and country-specific centre rather than the actual practices in the margins, particularly where these might include 
non-formal education using Arabic script and Islamic texts.

It may be worth mentioning here that depending on with which set of discourses one engages, Ethiopia, particularly the eastern and southern parts, which are the locus of this discussion, are characterised by drought and famine in the east, and devastating floods along the southern reaches of the Rift Valley. Climate change, resulting from escalating carbon emissions from industrialised nations, appears to contribute towards: increasing desertification and an exacerbation of environmental factors including drought and flooding which impinge on human life. Yet, the literature, particularly that of the World Bank and the IMF tend to ascribe famine to poor agricultural or pastoralist practices (see also, PACT 2008).

The argument in this article follows evidence of clearly formulated views on literacy, language and educational practices illustrated in the alternative or unconventional literature referred to above. It is triangulated with narrative data collected during a system-wide study of the medium of instruction used in Ethiopian primary schools (Heugh et al. 2007). These data also chime with a related study in Niger where despite the conventional portrayal of Muslim women as disempowered and silenced by Islam, Ousseina Aldiou advances strong evidence of the politics of agency amongst Muslim women in post-colonial Niger (O. Alidou 2005). This paper includes excerpts of the narratives of community leaders, educators and students ${ }^{2}$ who inhabit spaces characterised by their distance from the centre, in the Afar desert and along the Rift Valley towards the south of the country, in the Southern Nations, Nationalities and Peoples' Region (SNNPR). In the first set of narratives, an attempt is made to illustrate how a pastoralist community from the Afar desert, which typically might be cast as without voice or as unco-operative, in fact exhibits both voice and agency that resonate with local, regional, national and even international educational concerns. This community also offers counter evidence of co-operation and participation. In the second set of narrative excerpts, the juxtaposition of voice over time and space demonstrates that stance is neither static nor fixed. Mobilities of space and time permit adjustments to, and reinterpretations or reconfigurations of stance as different agents draw physically closer to and further away from the debates of the 'centre'.

\section{IN SEARGH OF NEW RESEARCH PRACTICE: NAVIGATING DICHOTOMIES OF PERIPHERY - CENTRE; AND HORIZONTAL - VERTICAL AXES OF LANGUAGE CHOICE}
Aliter lthough pre-colonial traditions of literacy and education, particularly Islamic traditions of Africa, predate de- velopments in Europe, contemporary Western texts encode Ethiopian social systems as not simply poor, but depend- ent upon external aid, educational exper- tise, languages, and legitimacy. Such aid arrives and is superimposed in a vertical arrangement over the horizontal axis. Whether or not the consequences of such structural arrangement are intentional, the effect is one in which only a few par- ticipants enter the vertical axis and thus the narrow corridor to bounty. This struc- tural arrangement places the researcher in an ambiguous position as of the 'centre' and all this holds, yet concerned with un- derstanding participants of peripheried contexts who transverse more versatile 
horizontal systems. The researcher is spatially mobile, crossing from international-metropolitan-urban proximities of power, towards the geographical contours of remote reaches. Physical and cognitive analytical mobility, however, are often disconnected on a temporal plane. In order to leave behind pre-prepared notions of language practices, literacy and educational needs, the researcher of the centre requires both a temporal and spatial journey in order to see and hear what it is that lies beneath the surface of intricate webs of social practices in remote settings. Purse-strings determine whether the researcher moves within the vertical or between the horizontal axes. Short-term consultancies will render predictable findings and analyses related to the templates of the centre which ultimately recommend solutions requiring the overlay of yet another set of vertical systems, to be implemented from the centre outwards. Litmus tests obtained by consultants who are urged to parachute into the hard-to-reach spaces will be unlikely to reveal the intricacies of women's resistance or parental participation; and (in)audible linguistic repertoires, 'functional multilingualism' (Heugh 1995) or multilinguality (Agnihotri, 2007). These bubble along horizontal axes with the assertion of 'linguistic citizenship' (see also Stroud and Heugh 2004, 2011) and agency (see also Kerfoot 2010).

Recent contributions which further the anthropologist's essential toolkit, i.e. peeling away metaphorical layers of the onion, to reach what it is that the respondent really might offer (notably, Hornberger and Johnson 2007), have informed numerous studies of language and literacy practices (e.g. in Shoba and Chimbutane 2013). A more recent volume on ethnographic research (McCarty 2011) is already regarded as essential to postgraduate studies of ethnographic research in applied linguistics. The studies included in these and other theories of ethnography correctly discuss the ethics and role of the researcher, however, the emphasis is usually towards methodologies for navigating through the protective coatings of the subject's position, in other words, the gaze is towards the informant. The focus here suggests a shift in which the focus is a consciously reflexive interrogation of the researcher's position as much as an investigation of that of the subject.

What has become evident is that there is a fundamental set of constraining factors in most consultancy-based 'research' or 'educational evaluations' in Africa (e.g. Alidou et al. 2006, Heugh 2011b). These serve to undergird the asymmetrical relationship between the international aid agency and the administrative architecture of the country in receipt of aid; between the administrative centre of the country and further flung regions and towns; and between the 'researcher' and the 'researched'. Such fragilities demand new theoretical and methodological research practice. This researcher has learned over time not to believe what is claimed in government offices about communities and their language practices where there is a significant distance (spatial, socio-economic, linguistic, and sometimes also faith-related) between the two. For example, during a research study intended to inform a provincial language policy in the Northern Cape, post-apartheid officials hoping for a convenient policy inclusive of only four language communities, assigned agents to monitor the researcher's fieldwork activities. There was a vigorous denial of the existence of speakers of a Khoe language, Gri, and various attempts to wish away the presence of San communities and to limit the fieldwork to as close as possible to the provincial capital, Kimberly. Nevertheless, 
by resorting to independent transportation, and after waiting for several hours in a community centre only 120 kilometres from Kimberly, about 200 self-identified speakers of Gri filtered slowly from the semi-desert on the outskirts of a small town towards the centre (Heugh 1998). In refusing to accept the silencing stance and 'governmentality' (Pennycook 2002) of the provincial administrators, the researcher was able to uncover significant views of language choice and identity within this community.

A distrust of the discursive narratives of stakeholders positioned in a vertical relationship to the researched was compounded by the uncovering of a litany of evaluations based on invalid instruments and unreliable reports of education systems during a 25-country study in sub-Saharan Africa (Alidou et al. 2006, Heugh 2011b). Efforts to silence the reporting of these flawed evaluations were brought to bear by powerful agencies which had been recipients of development aid as well as by a senior official responsible for allocating 25 years of World Bank funds towards theoretically compromised education programmes in Africa (Heugh 2009). When the administrative voice appears to speak on behalf of communities positioned as silent, there is every reason not to take this at face value.

On the one hand the methodological practice here literally involves a passage of time and the arduous physical overland journey to reach the difficult to reach spaces. The further one travels from the centre the more one is able to gather a multisensory experience of distance over time, and of the changing environmental, socio-economic and political landscapes. One is also more easily able to leave behind a cacophony of theories constructed elsewhere, conventional literature, and strongly held views of the powerful agents, all of which clutter the mind. The inner journey requires a reflexive research process in which the researcher consciously releases layers of pre-formulated and habituated positions of what to expect and what will be found. A conscious unlayering and acknowledgement of the researcher's own habituated practice offers intimate proximity to the scripts which remote communities have of themselves and their participation in local concerns as well as their engagement with the centre. This is simply because the more clearly one recognises one's own research and cognitive baggage, as well as one's own limitations, the more one is likely to recognise the filters which get in the way. If one recognises the expression of one's own linguistic citizenship, this allows one to be more sensitive towards it in others.

\section{GATHERING}

\section{ETHNOGRAPHIC DATA IN}

\section{THE FIELD}

$\mathrm{H}$ ducational researchers who reach Cthe margins encounter several sets of respondents. These include local and / or regional government agents, community leaders, women's groups, teacher trainers, teachers, teachers-in-training and school students. It is tempting to suggest that the regional and local education officials are often expert negotiators of the two axes. They appear to be deft at facilitating mobility along the vertical channels of communication between the centre and the local, and simultaneously they cohabit the horizontal spaces in which discourses of resistance may be detected. Narrative data collected during fieldwork stages of study mentioned earlier (Heugh et al. 2007) reveal contradictory representations of voice, agency and relationship towards language ecologies, over different points of time and space. ${ }^{3}$ 
The local education office (for example, a Zonal Education Bureau) is a locale in which official responses approximate those of the Regional Education Bureau, of which there are 11 in Ethiopia, and the federal Ministry of Education. A respondent, who offers responses which approximate the official position when located in the education office, may offer significantly nuanced alternatives during a journey which creates a physical distance from the administrative space, for example en route to a rural school. Subsequent to a rural school visit, the same respondent might offer a third set of responses - more complex and nuanced than either of the former. The parachute consultant/ researcher is unlikely to have the time to be in dialogue with respondents over different timeframes, and / or in different physical settings. Data collected under such limiting constraints are therefore likely to be one dimensional and fixed in time and space. Given what we know of ethnographic and anthropological research in other settings, the one-off data sample has serious limitations.

\section{LANGUAGE EDUCATION POLICY CONTEXT}

$\mathrm{T}$ The language education policy provides for eight years of regional or local language (often identified as home language/mother tongue) medium education (MTM); plus the teaching and learning of the federal 'working language' Amharic; plus the teaching and learning of English as subject in primary school; and English as a medium of instruction from the ninth grade (beginning of secondary school). Three regions have followed this policy exactly and the others have made their own adjustments which range from six years of MTM to four years or zero years depending upon contextual circumstances (see Benson et al. 2012 for a detailed account). Somali Region has implemented eight years of MTM education. Afar Region has not; it has implemented six years of Amharic as a second language for most students followed by a switch of medium to English. Afar, the home language of about $95 \%$ of people of this region is not used as the medium of instruction in schools other than a handful of Alternative Basic Education (ABE) schools established for pastoralist communities along the Afar depression (upper reaches of the Great Rift Valley). The Southern Nations, Nationalities and Peoples' Region (SNNPR), which extends southwards along the section of Rift Valley towards the border with Kenya, has the highest density of linguistic diversity in Ethiopia. It is also an area prone to regular annual flooding in contrast with the arid terrain of Afar to its north. This region initially implemented six years of MTM education in eight languages in addition to Amharic, potentially providing $85 \%$ of students of the region with an education in their home language. The regional policy in SNNPR was altered in 2004 to an earlier switch to English, after four years of MTM. Some students in the urban areas receive Amharic medium education even if this is a second language, especially if these students belong to minority languages of the locale.

\section{CONTEXTUAL}

\section{BACKGROUND OF THE SEMI AND DESERT REGIONS OF AFAR AND SOMALI REGIONS}

$\mathrm{M}$ ost of the people in Afar and Somali regions are pastoralists or nomadic. While there has been a dramatic increase in primary school enrolment across the country over the last decade, reaching $84 \%$ by 2010 , only about 20 to $30 \%$ of 
children of school-going age are enrolled in schools in Somali and Afar regions. Fewer than $5 \%$ of pastoralist children reach secondary. In one zone in Oromiya Region, there are only five schools for 50000 people (PACT Ethiopia 2008: 7); and in Somali Region the only secondary school is in Jijiga, the capital town of the region. Secondary schools in Afar are also only in the few urban hubs. Schools tend to be located in urban or village settings rather than along grazing routes or near water. Limited alternative basic education provision is sometimes made for pastoralist communities. Thus, neither the federal Ministry of Education nor the regional authorities actually make it possible for pastoralists to have easy access to school. However, from the centre, pastoralists are represented as uncooperative and intent on keeping their children out of school owing to their nomadic lifestyle and practices of early marriage, etc. The external perspective of pastoralist communities is predominantly characterised by pessimism, stigma and a static portrayal of people locked out of the whirlpool of globalisation. As mentioned earlier, in Afar and Somali regions, pastoralists are subjected to poverty and climate change. But this does not mean that they have inadequate knowledge of environment, thus development advice and aid based on such assumptions is often misplaced (cf. Cohen 2007). An alternative discourse includes criticism of the curriculum for making few connections between pastoralist and mainstream systems and it is said to be inflexible and insensitive to rhythms of pastoral life (PACT Ethiopia 2008).

The federal Ministry of Education which commissioned a study on the medium of instruction in Ethiopian primary schools in 2006 neither included pastoralist communities nor the Afar and Somali Regions in the original terms of reference for the study. This illuminates the (in)significance of the most marginalised, in this case also Islamic, communities in the country, relative to the centre.

\section{VOICE AND AGENGY WITHIN A PASTORALIST COMMUNITY IN AFAR}

Ginding pastoralist communities can 4 be challenging. One needs to be accompanied by a local official who has some idea about where the community may be located since mobile communities are seldom accessible by a regular road. A community at Dudub pastoralist village visited in October 2006 was at that time relatively stable and settled. The local (woreda) education office is located in the closest town, Awash, and this had facilitated the funds to assist the community to construct a school building close to the pastoral hamlet. The education officer was not prepared to accompany the team or to help us locate the school, but he did offer vague directions which amounted to 'travel north along the dry Awash River bed'. The driver and Ethiopian researcher were clearly apprehensive about this and not keen to venture into the unknown. However, we managed to find evidence of a pastoralist route, with empty or abandoned informal shelters that may have been used as temporary structures for community meetings or Qur'anic schools. At one point an armed herdsman with a team of camels intercepted the team, causing further disquiet for the driver and the Ethiopian researcher. Only after deft negotiations made it clear that none of the team was a native speaker of Amharic, or a government representative, were we able to continue. We eventually located the local authority sponsored alternative basic education school. Here we found the teacher and a few school students, none of whom was in 
class. After some persuasion they accompanied the researchers to the outskirts of the hamlet. We were unable to get close to the dwellings and girls and women were kept hidden away, perhaps because of a recent spate of abductions of young girls and the team, including one faranji (foreigner), was viewed with suspicion.

The village chairperson and a number of community representatives engaged in discussion with the researchers and the teacher in Afar with some Amharic and Afaan Oromo. One of our researchers spoke Tigrinya, while the driver spoke Afaan Oromo, and the teacher spoke Afar. All three were able to use Amharic as a vehicular language, as were several of the community representatives. So the discussion involved a complex repertoire of languages and interpretations. The driver and Ethiopian researcher provided double interpretation into English for this researcher. It became clear that this community had co-operated fully with the education authorities in relation to the construction of the school, but it was clear that the pastoralists believed that there had not been sufficient reciprocity:

The community has supplied free service, labour for construction and stools for students, and water during construction. There is a water pump to provide water for the children at school - but no generator so the school is not open... (Chairperson).

This explained why we had not found anyone in class earlier and the implication here was that the education bureau had not provided all the necessary resources to enable the school to open. The chairperson was careful with his criticism at first, but his point regarding the generator was heavily laden. Water to drink is essential for the students in desert conditions, and water for toilets is a necessity, most especially in order to retain girls in school. Whereas it might be possible for boys to attend school for morning sessions, lack of water would prevent girls from attending. This, rather than uncooperative pastoralists, would provide a contributory explanation regarding low attendance of girls in such settings. Since the chairperson had had an opportunity to voice an opinion, other members of the village committee were keen to volunteer information.

We [adults] would also like to learn in the evenings but there is no electricity... (Spokesperson 1).

Villagers, who had helped to build the school, had hoped for some rewards, including being able to participate in adult education, in order to engage with contemporary society. However, this wish had been dashed or delayed owing to poor planning or government ineptitude. Emboldened by the second criticism, another representative continued:

We would like to learn to read and write Afar, Amharic, mathematics, civics and English... (Spokesperson 2).

The sequenced list of subjects on the wish list is interesting. First mentioned in the local language of Afar people, then the national 'working language' Amharic is listed probably because it has vehicular traction, even though the community is noted for its resistance towards what it perceives as linguistic violence conducted by government through this language. Mathematics, which is third on the list, might have been predicted, is followed by civics, which suggests a willingness to participate in regional or national citizenship. Last on the list is English - suggesting a nod in the direction of globalisation and the promise of contact with the outside world. So the concerns here, in the middle of the desert, appear to be clearly articulated, demonstrating a connection between the local and the centre, and certainly not limited or disconnected from 
the global discourses. The chairperson, however, was not in complete agreement with this list, and he turned the discussion from the adults back towards the children and their needs:

The children should learn Afar and then English... (Chairperson).

The chairperson was careful to reveal his position, not through what he said, but through what he did not say. He omitted mention of Amharic, signaling his stance of resistance towards the language. To make sure that the researchers had not missed the point, this omission was picked up and made more explicit by the Spokesperson 1 who had earlier added to the chairperson's initial criticism of government:

Those Amharas must learn English and we don't need Amharic... (Spokesperson 1).

Here the matter is unambiguous, the use of 'those Amharas' signals a yawning socio-political chasm between the pastoralist community and those who govern them, and from this position, marks speakers of Amharic.

Afar is one of the regions which has not yet implemented the mother tongue medium principle in the mainstream schools located in towns. School pupils are taught through the medium of Amharic for the first six years even though they are speakers of Afar. Because Afar is a poor region, the federal government claims that it is providing more support to this region, however, neither the regional nor federal government is implementing explicit government policy here. In effect, the chairperson and spokesperson 1 are taking a highly political stance, and expressing this through their linguistic claim on citizenship. Secondly, they are clearly dismissing government-provided education as irrelevant for their children, 'we don't need Amharic'. It would therefore not be surprising if pastoralist parents are reluctant to send their children to mainstream schools where there was an illogical language mismatch, assuming they were able to access such schools. Viewed from the centre this might be cast as uncooperative behaviour on the part of Afar pastoralists. Viewed from the pastoralist perspective, communities not only have a right to exercise passive resistance, they exercise voice, linguistic citizenship and agency. Nevertheless, given the contribution of Spokesperson 2, earlier, the position towards Amharic was also multifaceted and there was clearly at least one alternative view of Amharic as part of the horizontal linguistic ecology. In fact, Spokesperson 2 was reflecting pragmatic linguistic reality of which each of the pastoralist informants made strategic use.

While pastoralists are frequently positioned anachronistically and accused of being sexist and paying less attention to their daughters' education, or keeping their daughters out of education, we found alternative claims:

Girls should go to Grade 8 or beyond. We used to think foolishly that ladies should not get education - now we know that first ladies must get education ... in Afar for Grades 1-4 for the foundation. From Grade 5 it should be English... (Chairperson).

Actually we want Afar and English [medium] to the end of secondary (Spokesperson 1).

The dialogue included several instances of the informants reinterpreting or reshading their responses. Spokesperson 1 continued a pattern of restating or emphasising for the researchers a key element in the chairperson's contribution. Here, he expresses an even stronger affiliation towards and confidence in the viability of Afar language throughout the 
schooling system. This is an interesting claim for the regional language, Afar, and the implication is of wishing to establish equilibrium between local needs and access to the international context. This point was continued in the following contribution, subsequent to a question from the Ethiopian researcher about the possible impact of English:

If you have confidence in the language and culture ... you should not be worried about loss of culture because of English... (Chairperson).

This was interesting on several levels. Firstly, the chairperson articulates the strength of the association between Afar language, identity and agency of this small mobile community. Secondly, the stance towards English is remarkable. That the response is so clearly articulated and well-argued suggests that the community had discussed this matter themselves and come to a clear decision about English in relation to their children's education. It also indicates that even remote communities are not immune to or disconnected with the symbolic capital of English as a proxy for access to participation within dominant international discourses of power.

The chairperson concluded with a statement in which he addressed a significant concern and point of resentment within the Afar community (also noted in Somali region) that owing to the paucity of school provision for pastoralist communities, the regional government tries to persuade pastoralists to enrol their children in boarding schools in the closest town and thus to study through Amharic to the end of Grade 6.

Our culture does not say we must send our children away [for primary or secondary education] (Chairperson).

Of course, this last statement might be interpreted by agents of the centre as confirming the non-co-operative stance of the Afar communities. However, the community clearly sees this as an act of symbolic, linguistic, cultural and faithbased violence which is deeply insensitive to Afar people and what matters to them. Disappointment and antipathy towards the authorities perhaps explained why it was that the education official had been reluctant to accompany the team on this unplanned leg of the fieldwork. In retrospect, this was fortunate for the team, as his presence may have altered what it was that the community members were prepared to reveal.

The data found here are consistent with those of Krätli (2001) who found that pastoralists are adapting to and are aware of global challenges. To this end they wish to inhabit complex worlds which involve neither the loss of their language nor culture but which do offer expanded repertoires. In a similar vein, Brocklesby et al (2009) points to the 'voice' and agency of women, as well as traditional and religious leaders, and through which pastoralists make clear their own sense of participatory citizenship. The latter also claim that both government and development agencies 'do not understand the diversity and dynamics of pastoralist communities' (Brocklesby et al 2009:4). In Afar, even if these communities are in difficult-to-find locations, they have expectations of government responsibility just as they claim their own right to participatory linguistic citizenship and acknowledge their own responsibility of agency.

\section{SOUTHERN NATIONS, NATIONALITIES AND PEOPLES' REGION (SNNPR)}

week after having been in Afar, the Aresearch team, travelled south, along the Great Rift Valley, this time following 
a flowing river and interconnected lakes, and circumventing the capital city/town of the region. Unlike the arid lowlands in Afar, this stretch of the Rift Valley is fertile and people are productively engaged in agriculture. This region is divided into several administrative zones, and is home to the majority of languages (56) and their communities in Ethiopia. It is therefore the most linguistically diverse region. Two language communities, Gamo and Gofa, are served by the Arba Minch Zonal Education Bureau. Arba Minch, the southern-most major town of the region, is relatively well-resourced with educational infrastructure. It boasts a teacher education college and a newly established university, as well as the Zonal Education Bureau and the next downward tier of local authority, the Rural Woreda Education Office. The research team arrived in Arba Minch over a long weekend and spent two days engaging in informal communication with locals in coffee shops and casual eating places, observing and monitoring language practices. The team found that Amharic and one language, Gamo, were being used interchangeably in the town. Knowledge or use of English was negligible. Officials in the Gamo-Gofa Zonal Education Bureau were expecting a team of four researchers and a senior official was assigned to provide assistance, information and access to schools in the zone (both urban and rural). The senior official initially identified the language policy and practice in this zone as follows:

Three languages are used as media of instruction in this zone....Amharic is used as the medium of instruction in the towns, but not outside the towns. Gamo language is used in rural areas [pause] and even in some urban areas. Gofa is also used as the mother tongue according to nationalities (Zonal official, personal communication, 24 October 2006).
There seemed to be an officially accepted distinction between the use of Amharic (the official 'working language of Ethiopia', the most commonly used language of the federal capital, Addis Ababa, and the default lingua franca in linguistically diverse administrative regions such as SNNPR), and regionally significant but fairly locally circumscribed languages like Gamo and Gofa. It turned out that the Gofa speaking area was about 200 kilometres away. The official seemed to be that Amharic was limited to the town/ urban settings, and that Gamo and Gofa were reserved for rural settings. However, the official partially corrected or mediated this to suggest some leakage of Gamo into the urban space of Arba Minch. A discussion took place about the change of language policy in the region from six years of mother tongue medium education (MTM) between 1994 and 2004 to four years after this. One member of the research team posed the following question to a group of education officials, 'Who decided to reduce the mother tongue medium of instruction from six years to four years in SNNPR?' The response was as follows: 'Some study made by experts - who took the idea to the officials.' The research team was unable to obtain more clarity about the identity of the experts at the zonal office, but the research team found some clues later in the day. When asked about community participation in the policy change, the officials conceded that the community was consulted after, rather than before, the change. While it appeared that the community was in agreement with the change, the reasons for this agreement were not immediately apparent to the researchers.

The research team split into two, one to go to the Arba Minch Teacher Training College (TTC) and the other to go to the Rural Woreda (district) Education office, and thence to a rural school. At the TTC 
our two researchers found that a noticeably strong presence of the English Language Improvement Programme (ELIP) had been evident in the Arba Minch Teacher Training College, coinciding with the change of regional language policy toward an earlier shift to English medium in primary school. ELIP had been initiated by a new federal minister of education in 2004 in Addis Ababa and it was led by a consultant from the UK who was a frequent visitor to the Arba Minch TTC. The researchers discovered that student teachers were urged to use only English at the college, to have 'English-only' days and weeks despite the absence of English in the local linguistic ecology. They were urged to develop English language materials, posters, newsletters etc., even though many would be teaching through Amharic, Gamo or Gofa for the first four grades of school. The ELIP team did not appear to encourage a similar degree of enthusiasm towards producing such resources in any Ethiopian languages, or to develop any bilingual or multilingual teaching resources, which might have seemed a worthwhile activity and more aligned with the linguistic practices of the town and surrounding areas.

The other researchers accompanied the zonal education official quoted above, on an outward journey to a rural primary school. The school is located approximately 60 kilometres north of Arba Minch along what was then a flooding river valley. This made the journey arduous and long. The outward journey included a discussion of the school system, education policy, community participation and teacher education. About 45 minutes into the journey, the official who had been using English to communicate with us, but Amharic and Gamo with other education officials in the zonal and rural education offices, made the following surprising statement: 'Amharic is not my language.
I speak only Gamo and English...' He volunteered a position which suggested some residual resentment of the enforced vertical use of Amharic during earlier political periods, and a sense of pride in the ascendency of regional languages of the south, including Gamo, but not Wolaita, a language with a larger linguistic community further to the north-west. There had been an attempt by linguists to 'harmonise' four closely related languages: Wolaita, Gamo, Gofa and Dawro into a hybrid language to be called 'Wogagoda', but this had resulted in an ethnolinguistic uprising in 1999 with speakers of the three smaller ethnolinguistic groups rejecting the move as a ruse to establish Wolaita dominance (see also Smith 2008).

It was an interest of the politicians to do this. And it was an interest of Wolaita to bring other language communities under Wolaita. But it was not popular (Zonal official).

An official reason given for the attempt to create the hybrid 'Wogagoda' was in order to reduce the costs of producing school learning materials in four languages. But the official rebutted this: 'The debate continues but the material costs are not so different'. Thus from his position in the zonal office, he was distancing himself from the next tier of government above him, namely the Regional Education Bureau and signalling distance from speakers of Wolaita in terms of political and linguistic identity. Given the lingering tension over this initiative, it was clear that communities played an active role in decisions which might alter the (perceived) balance of power amongst linguistic communities, and that individuals such as the education official had very strong views about such matters. $\mathrm{He}$ made it clear that his allegiance on this matter was with the communities, along the horizontal axis rather than with the 
administrative position. This appeared to be in contrast with his and the communities' apparent laissez-faire approach to the reduction of MTM from six years to four years. However, our informant suggested that in addition to the influence of the English language improvement initiative, there was a perception that an earlier switch to English medium might serve to allay tensions amongst different linguistic groups in the region, subsequent to the upheaval over 'Wogagoda'. The implication was that the communities were therefore in favour of the earlier change to English medium education, partly as this would circumvent any local political tensions over the use or rejection of the hybrid language.

When we reached the rural primary school, we were ushered into the principal's office. Although we were expecting to see and hear evidence of Gamo, we saw student records of enrolment, gender, attendance, timetables and other school materials displayed on the walls of the administrative quarters in Amharic and we heard the principal using Amharic to communicate with teachers we met along the corridors and in the staffroom. What we found in the primary classrooms was mostly Gamo and English: Gamo medium for the first four years and a mix of Gamo and English from the fifth year onwards. Amharic was present as a subject. So the official's earlier distinction of Amharic in the urban centres and Gamo in the rural context was not altogether borne out in this rural school, and there seemed to be clearly demarcated functions ascribed to the use of both Gamo and Amharic. Despite the primary school being in a small rural village, the school principal demonstrated highly sophisticated, articulate and complex positions relating to language choice, use and student achievement:
Students in this school always do well in the Ministry's exams in Gamo ... they would like to be able to study in Gamo in secondary school since they think that this would assist overall achievement...

The students who got the best achievement in Gamo (subject) were the ones who got the best scores for all areas of the curriculum...

Those who got poor results in Gamo were the ones who failed the national examinations ....

Teachers use Gamo and English side by side on the blackboard... (Rural school principal).

This contribution suggests that students express their linguistic citizenship in relation to education and that this is based in part on student achievement data from this school. Secondly, the principal refers to bilingual teaching and learning practices in the school. Classroom observation confirmed this practice particularly in the years immediately after the regional policy change to English medium, i.e. from fifth grade and above. Teachers were seen and heard to be using both Gamo and English side by side on the board. The principal, without any apparent training in bilingual methodology was encouraging his staff to use bilingual classroom strategies. Furthermore, he seemed to be making clear connections between language achievement and achievement across the curriculum, based on student data from his own school. This script conflicted in several ways with the official accounts from both the Regional and Zonal Education Bureaus.

Students say why not go to matric [end of secondary school] in mother tongue - students say they can develop their interest - now there is a short period of years using the mother tongue - students are wanting to 
continue (Rural school principal).

This further suggests student agency and claims of linguistic citizenship in relation to repertoires or multilinguality which has the best ecological fit with the local environment. However, the principal also reported that because of the pressure of Grade 10 national examinations in English, local community members had begun to ask if the schools should begin English medium even earlier than at present. Of course, there had been serious implications for those teachers most directly affected by the change in medium in the fifth grade. Teachers who had been teaching Grade 5 and 6 students in Gamo until 2004 did not have the English language expertise to effect the change and thus they were obliged to use codeswitching between Gamo and English. It became clear that the principal was supporting rather than chastising them for doing so, incorporating this practice into his own pragmatic philosophy which we had understood as bilingual methodology in our earlier conversation with him.

One of the notable aspects of this rural school was clear evidence of parental and community involvement. Parents constructed the classrooms and made benches and tables for the students from hand-hewn wood. The community set aside land to be used for the express purpose of generating an income from a mango plantation to supplement the finances of the school. A community centre was established in the school grounds, equipped with a generator and television so that village members could follow important sporting competitions, mainly soccer (African Cup etc.). So our experience of this rural school, although it was in a difficult-to-locate setting, far from the region's centre and relatively inaccessible from even the closest zonal centre, was that it was well-functioning, successful, supported by parents and the local community, and led by a dynamic principal. The principal, teachers, parents and students in this community seemed to exercise voice and agency, and expressed clear positions on matters of language use in education.

On the return journey to Arba Minch, we realised that the education official was uncomfortable about some of his earlier prepared scripts, particularly his earlier account of where and under which circumstances Amharic and Gamo were used. It was obvious that we had recognised that Amharic was being used for administrative purposes in the rural school, even if he had earlier informed us that we would only find Gamo in the rural areas. But it seemed that he needed to reiterate part of the prepared script before he could let go of this and acknowledge de facto language practices:

...People take the short-cut to a
good life - it is Amharic in the urban
areas but not the rural areas. High
schools, colleges and universities use
English. Hotels, restaurants, shops
... use Amharic. In the market place
it is Gamo. We are rich in languages
but poor in economy. [Pause] What
is the use of it? People love Amharic
and it is very useful. People tell jokes
in Amharic. It is not the language of
Amhara only, it is our language too
(Zonal official).

So, after having denied that he knew or used Amharic on the outward journey, he finally revised his script to reveal a more pragmatic use of Amharic for horizontal purposes as well as a sense of linguistic appropriation. So this informant held several contrary views of language and use, and we would not have discovered these had we only met him, once, in the zonal education office.

Later that day we visited an urban primary school which began with a brief 
meeting with the principal and was followed by a discussion with teachers in the staffroom. We were told that most students in this school were from poor families struggling to survive. Although many parents had little formal economic activity, and thus time on their hands, community participation in the school was negligible. Although Gamo was supposed to be the medium of instruction in the first four years, the principal informed us that the teachers had to 'translate' into Amharic, but he claimed to believe that it would be better to teach in English. However, it was clear that he was uncomfortable using English himself and he made his excuses to leave us as quickly as possible. How he could imagine that his teaching staff would be better equipped to use English in the classroom was to remain a mystery. We were left in the company of the deputy principal and several teachers, including the head of English. The English teacher who had been at the school for five years gave an account of all of the initiatives that he had introduced to improve English in the school during this time. However, he expressed a different opinion from the principal and suggested that students would learn more if they were allowed to learn through the medium of Gamo or Amharic beyond Grade 4. This clearly deviated from the accepted script of the school and the deputy-principal quickly intervened to reinterpret the English teacher, saying that the English teacher, did not, in fact, support the longer use of mother tongue medium. The deputyprincipal said that students and teachers could not express themselves well but that the solution was for all teachers to participate in the English Language Improvement Programme (ELIP). Some but not all the teachers at this school had already undergone the 120 hours of intensive training and possibly also another 80 hours of distance education. Since the ELIP training had been in place for about eighteen months, the researchers asked those teachers who had been exposed to ELIP to offer their views of the programme. Participating teachers initially offered almost identical, positive, reports of the programme that we had heard elsewhere in Somali and Harari Regions and also in Addis Ababa. However, after further conversation, they admitted that their early enthusiasm for the efficacy of the programme had been short-lived. They soon forgot most of what they had learnt because there was little opportunity to use English outside of the classroom. This we had also heard in other regions. Classroom observations at this school were carefully monitored by the deputy principal. He allowed us into only carefully selected classrooms, those of teachers who he thought were more proficient in the use of English. We found teachers reading bits of text-book material in English and asking students to respond to questions in ways that only required 'safe-talk' responses, for example:

Teacher: Is that so?

Student response: Yes, that is so.

The deputy principal was satisfied with these performances. On leaving the classroom, he did not notice the researcher lingering outside the classroom, eavesdropping on classroom discourse which switched back to more coherent and meaningful use of Gamo and Amharic for both students and teachers.

What we found in Arba Minch was that our informants expressed a range of often contradictory views about language preferences and practices. The closer the physical proximity to the regional office, the more the position was likely to mirror the accepted or official line of argument; the further away, the greater the latitude to differ. The principal in the rural 
school, at the furthest point from the reaches of the regional office, was able to express entirely contrary views to those of the principal and deputy principal of the urban school. We also found that in the urban school, the deputy principal felt obliged to revise the script of the English teacher to one which mirrored his own, that of the principal, and also the official script of the Zonal, Regional and Federal education structures. And we found that the education official who accompanied us to and from both the rural and urban schools revised his own scripts over time and changes of location. If government agents of the administrative centre, Addis Ababa, exert power, this is to influence the acquiescence of regional and local government officers. The further the distance from the centre, the weaker are the ties; the closer to the centre, the stronger they appear.

The point being laboured here is that the collection of data needs to be done over different temporal and spatial dimensions in order that more than oneoff static snap-shots are taken of what are complex ecologies, contradictions and horizontal patterns of behaviour. Such ecologies manifest multiple positions at administrative, community, school and even individual levels, often differing from the vertical patterns orchestrated by administrative structures.

\section{CONCLUSION}

Tarratives included in this paper illus1 trate that spatial and socio-political proximity to the centre seem to correlate or synchronise with dominant representations and vertical forms of language planning activities. Regional agents and other stakeholders further from the centre appear to have greater latitude to claim positions which reject policy and practices which have been layered over local ecologies. What we also found were contradictory representations of voice, agency and language ecologies in contexts which might be characterised as on the margins of a poor country. Narrative accounts have been introduced from two locations, one a remote pastoralist community in the Afar desert and the other a set of communities, including rural and urban, in a predominantly agricultural region of SNNPR. Several observations may be made of these. The first is that the spatial and socio-political proximity to and/or interest in the centre appears to exert pressure towards a synchrony with dominant representations and vertical language planning activities. Those who appear to be under the watchful eye of government agents adhere to the preprepared scripts and act to reformulate those which deviate. The spatial and socio-economic distance from the centre and its proxy, in this case, educational administrative structures, permits a greater degree of agency, resistance and alternative voice, as evidenced by a rural school principal and pastoralist community spokespersons. The third observation is that despite political antipathy towards the former language of vertical control, people make opportunistic use of Amharic for pragmatic purposes, even if they declare other allegiances and preferences. The fourth point is that citizens of the margins have a clear set of priorities relating to their linguistic citizenship (cf. Stroud 2001, Stroud and Heugh 2004) and this includes a pride in their local or regional language and desire to have access to English. The one does not preclude the other, and communities express and demonstrate that they use their linguistic repertoires for both horizontal and vertical purposes, and they have strong views about how and when they wish to do so. 
There are therefore complex matrices of voice and agency which include linguistic and cultural repertoires, engagement and participation. Scripts of the centre which claim that communities on the fringes are disconnected or unco-operative, or without voice and agency, miscalculate and are requiring of revision. There are implications here for the way in which short-term consultancies and evaluations are conducted in African settings. More specifically, in ethnographic research which needs to take account of people in remote settings, the researcher needs to uncover layers of his or her own habituated practices and which pressures have led to his or her own linguistic citizenship. This is essential in order to recognise that such research between researcher and informant is dialogic and recursive, and requires removing the shadows and veils which obscure meaning equally for both sets of participants in the process. A multi-directional understanding of linguistic citizenship seems to offer an added dimension to contemporary ethnographic research theory. The final point to be made is that communities of the centre appear to have become immobilised by their own anachronistic scripts which are vulnerable to out-of-focus snap-shots of mirages in the desert. The communities of the fringe, on the other hand, demonstrate their mobility along many different dimensions of time and space.

\section{ENDNOTES}

${ }^{1}$ I should like to thank Christopher Stroud and two anonymous reviewers for valuable comments and suggestions regarding an earlier draft of this paper.

${ }^{2}$ Narratives collected by the author, during extended fieldtrips in 2006.

${ }^{3}$ The original terms of reference for the study was that it would be a 4-6 week consultancy during which time a team of three researchers was expected: to develop research instruments; to plan the logistics of the field research; to visit five regions, including the city-state of Addis Ababa; to draft a report; to run a twoday workshop and present the draft report to representatives from across all eleven regions; and then to finalise the report in response to feedback from the federal and regional education officials. It was intended that the research team would fly to the capital city of each of the other four designated regions and conduct research within a limited radius of these. These terms of reference, apparently normal for a consultancy, were clearly inadequate if any reliable or valid research were to be undertaken. The terms of reference were altered so that it became a research project of the Human Sciences Research Council of South Africa, and closer to the system-wide research processes which this organisation undertakes. A second international researcher was invited to join the team so that two subteams, each with one international and one Ethiopian researcher, could be formed. The team leader insisted on overland travel for the most part, and in consultation with the two Ethiopian researchers, on visiting nine (rather than five) of the eleven regions (including one city-state). The team worked around the clock seven days a week in order to collect as much data as possible, in reality taking four times as long as originally intended for data collection and preliminary analysis; and substantially longer for further and secondary analysis. This was still not long enough, but an improvement on what may have been.

\section{REFERENCES}

Agnihotri, Rama Kant. 2007. Towards a pedagogical paradigm rooted in multilinguality. International Multilingual Research Journal 1(2): 7988.

Alidou, Hassana. 2004. Medium of instruction in post-colonial Africa. In James Tollefson and Amy Tsui (eds). Medium of Instruction Policies: Which Agenda? Whose 
Agenda? Mahwah and London: Lawrence Erlbaum. 195-214.

Alidou, Ousseina. 2005. Engaging Modernity: Muslim Women and the Politics of Agency in Postcolonial Niger. Madison and London: University of Wisconsin Press.

Alidou, Hassana, Aliou Boly, Birgit BrockUtne, Yaya Satina Diallo, Kathleen Heugh, and H. Ekkehard Wolff. Optimizing learning and education in Africa - the language factor. A stocktaking research on mother tongue and bilingual education in Sub-Saharan Africa. Paris: Association for the Development of Education in Africa (ADEA). < http:// www.adeanet.org/adeaPortal/adea/biennial-2006/doc/document/B31_MTBLE en.pdf $>$

Bamgbose, Ayo. 2000. Language and Exclusion: The Consequences of Language Policies in Africa. Münster, Hamburg and London: Lit Verlag.

Benson, Carol, Kathleen Heugh, Berhanu Bogale and Mekonnen Alemu Gebre Yohannes 2012. Multilingual education in Ethiopian primary schools. In Tove Skutnabb-Kangas and Kathleen Heugh (eds). Multilingual Education and Sustainable Diversity Work: From Periphery to Center. New York and Oxford: Routledge. 32-61.

Brocklesby, Mary Ann, Mary Hobley, Patta Scott-Villiers. 2009. 'Raising voice securing a livelihood'. The role of diverse voices in securing livelihoods in pastoralist areas of Ethiopia - a summary paper. Pastoralist Consultants International. $<$ www.pastoralists.org $>$

Carr-Hill, Roy and Edwina Peart. 2005. The Education of Nomadic Peoples in East Africa. Review of Relevant Literature. Paris and Tunis: UNESCO Institute for Educational Planning and the African Development Bank.

Cohen, Gideon. 2007. Mother tongue and other tongue in primary education: Can equity be achieved with the use of different languages? In Hywel Coleman (ed.). Language and Development: Africa and Beyond. Addis Ababa: The British Council. 6275 .
CSA (Central Statistical Agency of Ethiopia). 2007. Population and Housing Census of 1994 metadata and documentation. < http:// www.csa.gov.et/surveys/Population\%20 and\%20Housing\%20Census\%201994/ survey0/index.html>

Foucault, Michel. 1977. Discipline and Punish: The Birth of the Prison. Translated by A. Sheridan. New York: Pantheon Books.

Heugh, Kathleen. 1995. Disabling and enabling: implications of language policy trends in South Africa. In Rajend Mesthrie (ed.). Language and Social History: Studies in South African Sociolinguistics. 329-350. Cape Town: David Philip

Heugh, Kathleen. 1998. Considerations for and background to the draft language policy for the Northern Cape. Unpublished paper. Cape Town: Project for the Study of Alternative Education in South Africa, PRAESA, University of Cape Town.

Heugh, Kathleen. 2006. Language education policies in Africa. Encyclopaedia of Language and Linguistics. $2^{\text {nd }}$ Edition. Elsevier Science. 6: 414-423.

Heugh, K. 2009. Literacy and bi/multilingual education in Africa. In Tove Skutnabb-Kangas, Robert Phillipson, Ajit K. Mohanty and Minati Panda (eds). Multilingual Education for Social Justice. New York and Bristol: Multilingual Matters. 103-124.

Heugh, Kathleen. 2011a. Discourses from without, discourses from within: women, feminism and voice in Africa. Current Issues in Language Planning 12 (1): 89-104.

Heugh, Kathleen. 2011b. Theory and practice - language education models in Africa: Research, design, decision-making and outcomes. In Adama Ouane and Christine Glanz (eds). Optimising Learning, Education and Publishing in Africa: The Language Factor. A Review and Analysis of Theory and Practice in Mother-tongue and Bilingual Education in Sub-Saharan Africa. Hamburg and Tunis Belvédère: UNESCO Institute for Lifelong Learning (UIL) and the Association for the Development 
of Education in Africa (ADEA)/African Development Bank. 105-156. < http:// unesdoc.unesco.org/images/0021/ 002126/212602e.pdf>

Heugh, Kathleen, Carol Benson, Berhanu Bogale, and Mekonnen Alemu Gebre Yohannes. 2007. Final report: Study on Medium of Instruction in Primary Schools in Ethiopia. Addis Ababa: Ministry of Education. < http://www.hsrc.ac.za/ research/output/outputDocuments/ 4379 Heugh_Studyonmediumofinstruction. $\operatorname{pd}>>$

Hornberger, Nancy, and David Johnson. 2007. Slicing the onion ethnographically: Layers and spaces in multilingual language education policy and practice. TESOL Quarterly 41 (3): 509-532.

Jaffe, Alexandra. 1999. Ideologies in Action: Language Politics on Corsica. Berlin: Mouton de Gruyter.

Kabbaj, Omar and Matsuura, Kö̈chiro. 2005. Foreword. In Roy Carr-Hill and Edwina Peart. The Education of Nomadic Peoples in East Africa. Review of Relevant Literature. Paris and Tunis: UNESCO Institute for Educational Planning and the African Development Bank. 5-6.

Kerfoot, Caroline. 2010. Changing perceptions of literacies, language and development. Dissertations in Bilingualism 18. Stockholm: Centre for Research on Bilingualism, Stockholm University.

Krätli, Saverio. 2001. Education Provision to Nomadic Pastoralists: A Literature Review. Brighton: World Bank - Institute of Development Studies (IDS) <http://www. eldis.org/ fulltext/saverio.pdf $>$

Kroskrity, Paul (ed.). 2000. Regimes of Language: Ideologies, Polities, Identities. Santa Fe: School of American Research.

Laitin, David. 1993. The game theory of language regimes. The emergent world language System. Le système linguistique mondial en formation. International Political Science Review / Revue internationale de science politique 14(3): 227-239.

Maxey, Kees. 2004. 'Education for All - is it feasible for pastoralists?' Pastoralists and Education: Towards Integrated Education for Sustainable Community Development in the Horn of Africa. Indigenous Knowledge Systems Research and Development Studies No. 5. The Hague: PENNHA/LEAD-UL.

McCarty, Teresa. 2011 Entry into conversation: introducing ethnography and language policy. In Teresa McCarty (ed.). Ethnography and Language Policy. New York: Routledge. 1-28.

MoE (Ministry of Education). 1994. Education and Training Policy. Addis Ababa: St. George Printing Press.

Obanya, Pai. 1999. The Dilemma of Education in Africa. Dakar: UNESCO Regional Office.

Ouane, Adama. 2003. Introduction: The view from the linguistic jail. In Adama Ouane (ed.). Towards a Multilingual Culture of Education. Hamburg: UNESCO Institute of Education. 1-22.

PACT Ethiopia. 2008. Education for Pastoralists: Flexible Approaches, Workable Models. USAID and PACT Ethiopia. $<$ http://www.pactworld.org/galleries/ethiopia/Education \%20for \%20Pastoralists-A4. pdf $>$

PCC (Population Census Commission). 2008. Summary and Statistical Report of the 2007 Population and Housing Census. Federal Democratic Republic of Ethiopia. Addis Ababa: UNFPA. < http://www.csa.gov.et/ pdf/Cen2007_firstdraft.pdf>

Pennycook, Alistair. 2002. Language policy and docile bodies: Hong Kong and Governmentality. In James Tollefson (ed.). Language Policies in Education: Critical Issues. Mahwah, NJ: Lawrence Erlbaum Associates. 91-110.

Said, Edward. 1979. Orientalism. New York: Vintage Books.

Shoba, Jo Arthur and Feliciano Chimbutane (eds). 2013. Bilingual Education and Language Policy in the Global South. London and New York: Routledge.

Smith, Laura. 2008. The politics of contemporary language policy in Ethiopia. Journal of Developing Societies 24(2): 207-243. < http://jds.sagepub.com/cgi/ reprint/24/2/207>

Stroud, Christopher and Kathleen Heugh. 2004. Language rights and linguistic citizenship. In J. Freeland and D. Patrick. 
(eds). Language Rights and Language Survival: Sociolinguistic and Sociocultural Perspectives. Manchester, UK: St. Jerome Publishing. 191-218..

Stroud, Christopher and Kathleen Heugh. 2011. Language in education. In Rajend Mesthrie (ed.). Cambridge Handbook of Sociolinguistics. Cambridge: Cambridge University Press. 413-429.
Stroud, Christopher. 2001. African mother tongue programs and the politics of language: linguistic citizenship versus linguistic human rights. Journal of Multilingual and Multicultural Development. 22 (4): 339-355. 